Article

\title{
Protection of Mild Steel by Waterborne Epoxy Coatings Incorporation of Polypyrrole Nanowires/Graphene Nanocomposites
}

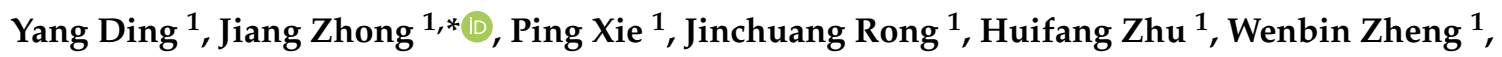 \\ Jinglan Wang ${ }^{1}$, Fei Gao ${ }^{1} \mathbb{D}$, Liang Shen ${ }^{1, *}$, Haifeng $\mathrm{He}^{1}$ and Ziqiang Cheng ${ }^{2} \mathbb{D}$ \\ 1 Jiangxi Engineering Laboratory of Waterborne Coating, Department of Coatings and Polymeric Materials, \\ Jiangxi Science and Technology Normal University, Nanchang 330013, China; dingy0128@163.com (Y.D.); \\ ordinaryxp@163.com (P.X.); rjcpolymer@163.com (J.R.); sunnnyzhf@163.com (H.Z.); \\ zhengweb1128@163.com (W.Z.); jxncwj1@163.com (J.W.); feigao2016@jxstnu.com.cn (F.G.); \\ hehf0427@jxstnu.com.cn (H.H.) \\ 2 Department of Applied Physics, School of Science, East China Jiaotong University, Nanchang 330013, China; \\ zqcheng_opt@126.com \\ * Correspondence: jiangzhong@jxstnu.com.cn (J.Z.); liangshen@jxstnu.com.cn (L.S.); \\ Tel.: +86-0791-83972752 (J.Z.)
}

Received: 31 October 2019; Accepted: 29 November 2019; Published: 3 December 2019

\begin{abstract}
Polypyrrole nanowires/graphene (PPyNG) nanocomposites as anticorrosive fillers were prepared by in situ polymerization in order to improve the anticorrosion performance of waterborne epoxy coatings. Field emission scanning electron microscope (FESEM) and Fourier transform infrared spectroscopy (FTIR) characterized the morphologies and structures of the synthesized PPyNG. The polypyrrole nanowires with about $50 \mathrm{~nm}$ in diameter were obtained. Conjugation length of PPy was increased with the addition of graphene. Open circuit potential (OCP) measurements, Tafel polarization curves, and electrochemical impedance spectroscopy (EIS) using an electrochemical workstation evaluated the anticorrosion properties of the waterborne epoxy/PPyNG coatings (EPPyNG). The studied nanocomposite coating possessed superior corrosion protection performance when the graphene content of the filler was $2 \mathrm{wt} \%$. Its corrosion rate was about 100 times lower than that of neat epoxy coating. The higher barrier properties of nanocomposite coating and passivation effect of polypyrrole nanowires were beneficial in corrosion protection.
\end{abstract}

Keywords: polypyrrole nanowires; graphene; waterborne epoxy; corrosion protection

\section{Introduction}

Metal corrosion is a disturbing phenomenon in which chemical or electrochemical reactions damage metal materials. It would not only result in economic losses, but also threaten the safety of industrial production. Many methods for corrosion protection have been developed, such as environmental modification, anodic protection, cathodic protection, protective coatings, and corrosion inhibitors, or any combination thereof [1-3]. Among them, polymer coatings are the most common approach for protecting metal surface from corrosion due to their low cost and high anticorrosion performance. For instance, especially, epoxy coatings have attracted many researchers due to their strong adhesion to substrates and excellent mechanical properties. However, even these coatings fail over prolonged exposure in corrosive media [4]. Many researchers have investigated polymer composites incorporating various functional fillers [5], such as montmorillonite [6], carbon nanotubes [7], graphene [8], and intrinsically conducting polymers (ICPs) [9], to overcome this problem. 
ICPs have attracted tremendous attention due to a wide range of potential applications in sensors, supercapacitor electrodes, biological industries, and corrosion protection $[10,11]$. In the anticorrosion field, the ICPs can be used to form a protective barrier layer and release inhibitors in the coating [12]. Among the available ICPs, polypyrrole (PPy) is the most promising polymer due to its easy polymerization, mechanical stability, and better biocompatibility, as well as tunable electrical property [13]. The electroactive nature of PPy allows for it to oxidize the metal substrate, which results in the formation of a passive oxide layer at the interface between the PPy and underlying metal substrate [14]. PPy is an excellent candidate for replacing hexavalent chromate, since it shows anticorrosion performance that is similar to that found for chromate [6,15]. Loading PPy can also enhance the corrosion inhibiting properties of zinc-filled epoxy coatings [16,17]. The surface treatment of pigment with PPy is found to be beneficial to the anticorrosion and mechanical properties of the epoxy paint [18].

Despite these advantages, the aggregation tendency of PPy particles is a major restriction of the processing and application of epoxy/PPy coating. Integration with montmorillonite and graphene turns out to be an effective method for avoiding aggregations and improve dispersion of PPy in the polymer matrix, which contributes to a great corrosion protection enhancement $[6,19,20]$. Graphene has higher aspect ratio than clay platelet, which can simultaneously improve not only the barrier properties, but also several mechanical, functional, and thermal properties of epoxy coatings [21,22]. The synergistic effect of PPy/graphene greatly enhances the anticorrosion performance of epoxy coating [23].

PPy with one-dimensional nanostructure, such as nanotube [24], nanorod [25], and nanowire [26], are used in various applications including sensors, supercapacitors and battery electrodes $[13,27,28]$. Up to now, there has been no report on using PPy nanowire as additive for waterborne anticorrosion coatings. In this paper, the PPy nanowires (PPyN) were prepared by a soft template method. The PPyN/graphene (PPyNG) nanocomposites were synthesized through in situ polymerization. The molecule structures and morphologies of the PPyNG nanocomposites were also analyzed. After that, the PPyNG nanocomposites were incorporated into waterborne epoxy coatings to study their anticorrosion performance for mild steel. For the convenience discussion, the present nanocomposite referred to as PPyNG, and nanocomposite coating corresponded to the epoxy/PPyNG coating.

\section{Materials and Methods}

\subsection{Materials}

The pyrrole monomer was purchased from Aladdin Bio-Chem Technology Co., Ltd. (Shanghai, China). Ammonium persulfate (APS), potassium permanganate $\left(\mathrm{KMnO}_{4}\right)$, sulfuric acid $\left(\mathrm{H}_{2} \mathrm{SO}_{4}\right)$, hydrogen peroxide $\left(\mathrm{H}_{2} \mathrm{O}_{2}\right)$, N-methyl pyrrolidone (NMP), Sodium chloride $(\mathrm{NaCl})$, and cetyltrimethylammonium bromide (CTAB) were obtained from Sinopharm Chemical Reagent Co., Ltd. (Shanghai, China). The flake graphite powder (325 mesh) was purchased from Sigma-Aldrich Chemicals (Shanghai, China). All of the chemicals were of analytical reagent grade and used without further purification. Hexion Inc. (Columbus, Ohio, US) provided waterborne epoxy resin (Epikote 6520-WH-53) and curing agent (Epikur 8538-Y-68). The Q235 mild steels (C: 0.14\%, Mn: 0.3\%, S: $0.05 \%, \mathrm{P}: 0.045 \%$, and rest being $\mathrm{Fe}$ ) with area of $42 \mathrm{~mm} \times 10 \mathrm{~mm}$ were purchased from Biuged Laboratory Instruments (Guangzhou) Co., Ltd. (Guangzhou, China). The mild steels were polished while using 400 grift sand papers and then cleaned in ethanol and acetone.

\subsection{Preparation of Graphene}

Graphene was prepared by following the method by Dong et al. [29]. In brief, $100 \mathrm{~g} \mathrm{KMnO}_{4}$ ( $1 \mathrm{wt} \%$ equiv.) was added in batches into concentrated $\mathrm{H}_{2} \mathrm{SO}_{4}(2 \mathrm{~L}, 98 \%$ ) over a period of $45 \mathrm{~min}$. in an ice-water bath. $100 \mathrm{~g}$ graphite (1 wt \% equiv., $325 \mathrm{mesh}$ ) was then added in batches under stirring at $35^{\circ} \mathrm{C}$ for $2 \mathrm{~h}$. The black flakes were filtered through a 200-mesh sieve and poured into $2 \mathrm{~L}$ of ice water after reaction. Subsequently, $30 \mathrm{wt} \% \mathrm{H}_{2} \mathrm{O}_{2}$ was added to decompose the insoluble manganese 
dioxide. The wet powders of pretreated graphite were obtained after filtering and washing. Pretreated graphite was then dispersed in the alkali water $(\mathrm{pH}=14)$ under ultrasonication while using a sonic vibra-cell VC505 processor in $60 \%$ power for $1 \mathrm{~h}$, resulting in black graphene slurry. The graphene slurry was centrifuged at 10,000 rpm for $10 \mathrm{~min}$. and then repeatedly washed by a large amount of water (4-6 times) until $\mathrm{pH}$ approached 10. The prepared graphene was re-dispersed in N-methyl pyrrolidone (NMP) for further use.

\subsection{Synthesis of PPy Nanowires/Graphene Nanocomposites}

The PPy nanowires/graphene nanocomposites (PPyNG) were synthesized through in situ chemical oxidative polymerization. In a typical process, $0.31 \mathrm{~mL}$ pyrrole monomer and $0.91 \mathrm{~g}$ CTAB were added in a mixture of $125 \mathrm{~mL} 0.2 \mathrm{M}$ hydrochloric acid and graphene-NMP dispersion and stirred for $2 \mathrm{~h}$ at ambient temperature, and then cooled to $0-5^{\circ} \mathrm{C}$. A precooled aqueous solution of $10 \mathrm{~mL}$ $0.2 \mathrm{M} \mathrm{HCl}$ containing $4 \mathrm{mmol}$ APS was added into above solution in batches. The reaction was allowed to proceed under stirring for $4 \mathrm{~h}$ at about $0-5^{\circ} \mathrm{C}$. The resulting product was filtered and rinsed with deionized water and ethanol (4-6 times) until the filtrate was colorless. Finally, the product was dried in a vacuum oven at $40{ }^{\circ} \mathrm{C}$ for $24 \mathrm{~h}$. The weight ratio of pyrrole to graphene varied as 99:1, 98:2, 97:3, and the resulting black composites were named as PPyNG1, PPyNG2, and PPyNG3, respectively. For comparison, neat PPy nanowires (PPyN) were fabricated by similar method absence of graphene dispersion.

\subsection{Fabrication of Nanocomposites Coatings}

The investigated coatings in this study consisted of the epoxy without the addition of filler as well as with the incorporation of PPy nanowires and PPy nanowires/graphene as the functional additives. Three weight concentrations of PPy nanowires additives had been prepared in order to achieve the optimal level of additives, and their anticorrosion properties are shown in Supplementary Materials, Figure S1 and Figure S2. The $0.5 \%$ additive based on the total formulation was finally determined. The preparation procedure was as follows. Firstly, the PPy nanowires and PPyNG nanocomposites were completely dispersed in $10 \mathrm{~mL}$ of deionized water with a high-speed dispersion and then added into $30 \mathrm{~g}$ waterborne epoxy resin. Next, $10 \mathrm{~g}$ curing agent was added into the above dispersive media and the mixture was painted on the pretreated mild steels. The resulting coating was obtained after curing for $48 \mathrm{~h}$ at room temperature. The prepared epoxy coatings that were loaded with PPy nanowires, PPyNG1, PPyNG2, and PPyNG3 were denoted as EPPyN, EPPyNG1, EPPyNG2 and EPPyNG3, respectively. The dry coating thickness was around $37 \mu \mathrm{m}$. For comparison, the neat epoxy coating was also prepared through a similar method without loadings, which was named Blank. Figure 1 shows the preparation process for the fabrication of waterborne epoxy/PPyNG coatings (EPPyNG) coating materials.

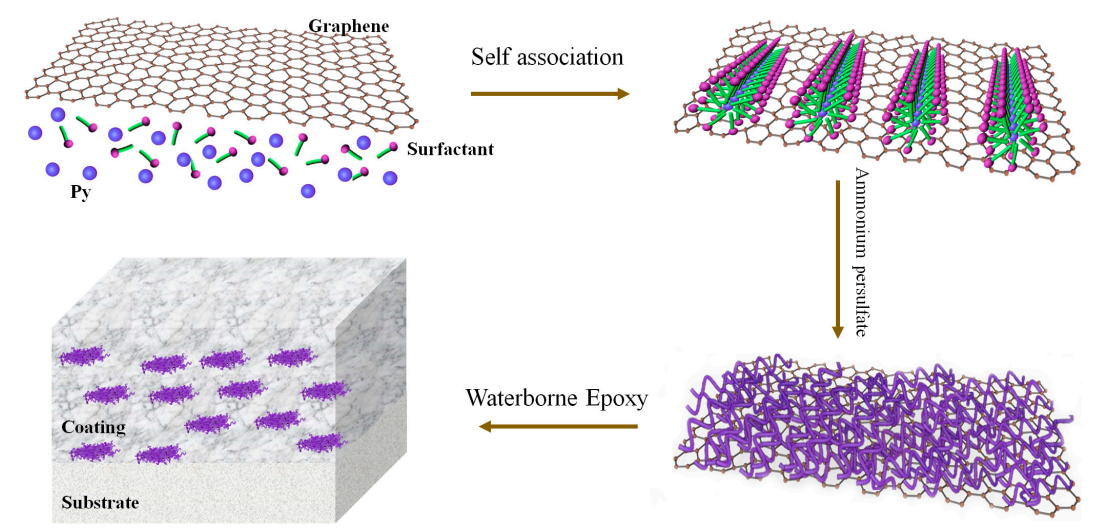

Figure 1. Schematic illustration of the preparation of waterborne epoxy/PPyNG coatings (EPPyNG) nanocomposite coatings. 


\subsection{Characterization}

The Fourier transform infrared spectrometer (FTIR) spectra of PPyNG films were collected by a Bruker-Veretex70 spectrometer (Bruker Company, Karlsruhe, Germany) while using KBr pellets. The scanning electron microscopy (SEM) images of PPyN and PPyNG composites were obtained while using a Zeiss Sigma FE-SEM (Carl Zeiss AG, Geraniah, Germany). The electrochemical measurements were carried out to characterize the anticorrosive properties of blank epoxy, EPPyN and EPPyNG coatings using a CHI 660E electrochemical workstation (Chinstruments Co., Ltd., Shanghai, China) that was equipped with a conventional three-electrode cell with a saturated calomel electrode (SCE) as reference, a platinum counter electrode with $1 \mathrm{~cm}^{2}$ area, and a working electrode. The bare mild steels or mild steels with coatings were sealed while using sealant (paraffin: Rosin $=1: 1$ ) and Teflon to leave $1 \mathrm{~cm}^{2}$ area opening to the electrolytic solution. The electrolyte was $3.5 \mathrm{wt} \% \mathrm{NaCl}$ solution. Open-circuit potential (OCP) was recorded for the blank epoxy, EPPyN and EPPyNG coatings up to 30 days of immersion time. The potential dynamic polarization curves of blank epoxy, EPPyN, and EPPyNG coatings were performed with a sweep rate of $2 \mathrm{mV} / \mathrm{s}$ from the cathodic direction to the anodic direction. The electrochemical impedance spectroscopy (EIS) measurements were collected in the frequency range of $100 \mathrm{kHz}$ to $0.01 \mathrm{~Hz}$ while using an alternating current signal with the amplitude of $5 \mathrm{mV}$. All of the electrochemical tests were conducted at room temperature. A ZQ-401 microscope was used to record the optical microscopic images of EPPyN coatings (Zhiqi Co., Ltd., Shanghai, China).

\section{Results}

Figure 2 shows the FTIR spectra of the PPyN and PPyNG nanocomposites. The broad band at $3000-3500 \mathrm{~cm}^{-1}$ arose from $\mathrm{N}-\mathrm{H}$ stretching vibrations [30]. The characteristic polypyrrole peaks located at 1558 and $1478 \mathrm{~cm}^{-1}$ were due to the asymmetric and symmetric ring-stretching modes, respectively [31]. The bands at 1048 and $1321 \mathrm{~cm}^{-1}$ were attributed to $\mathrm{C}-\mathrm{H}$ deformation vibrations and C-N stretching vibrations, respectively [32]. In addition, the peaks that were centered at 1202 and $923 \mathrm{~cm}^{-1}$ were assigned to the doping states of PPy [33]. When comparing to the FTIR spectra of PPyN, all peaks had also appeared in the PPyNG nanocomposites. It was worth noting that the $\mathrm{C}-\mathrm{N}$ stretching vibrations peak of PPyNG nanocomposites had been downshifted to $1310 \mathrm{~cm}^{-1}$, which was probably due to the $\pi-\pi$ interactions between graphene layers and aromatic polypyrrole rings [34]. Moreover, the ratio between the peak area of the skeletal band $1478 \mathrm{~cm}^{-1}$ and oxidization state sensitive $1558 \mathrm{~cm}^{-1}$ band $\left(I_{1478} / I_{1558}\right)$ could be used to calculate the conjugation length $[35,36]$. The ratio was $0.1304,0.1328$, 0.1427, and 0.1515 for PPy, PPyNG1, PPyNG2, and PPyNG3, respectively, which suggested that the conjugation length increased with further incorporation of the graphene. It might be ascribed to the fact that the strong interfacial interaction between PPy and graphene induced more electrons that were delocalized either in the pyrrole units or in the benzene ring units of graphene [35,37].

Figure 3 shows the morphologies of pure PPyN and the PPyNG nanocomposites. The SEM image (Figure 3a) revealed the uniform nanowire structure with an average diameter of about $50 \mathrm{~nm}$ and length of several micrometers. For PPyNG1 and PPyNG2 nanocomposites (Figure 3b,c), PPy held its wire-like morphology with a similar size to pure PPyN. However, from Figure 3d, the granular morphology of PPyNG3 was observed. The isolated graphene nanosheets could also be seen due to increasing concentration of graphene nanosheets. The result of the SEM images indicated that the morphology of PPy nanowires was affected by the higher content graphene. Similar phenomenon was observed in other's research [38]. 


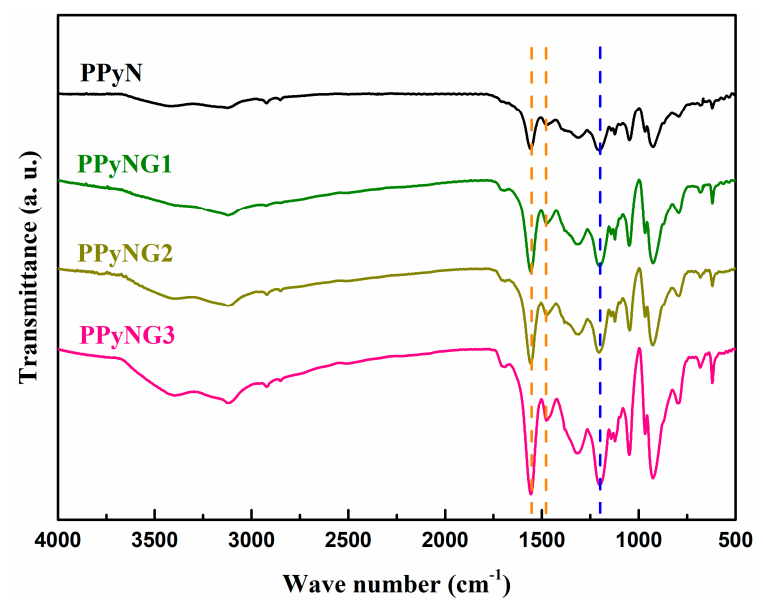

Figure 2. Fourier transform infrared spectroscopy (FTIR) spectrum of the PPyN, PPyNG1, PPyNG2, and PPyNG3.

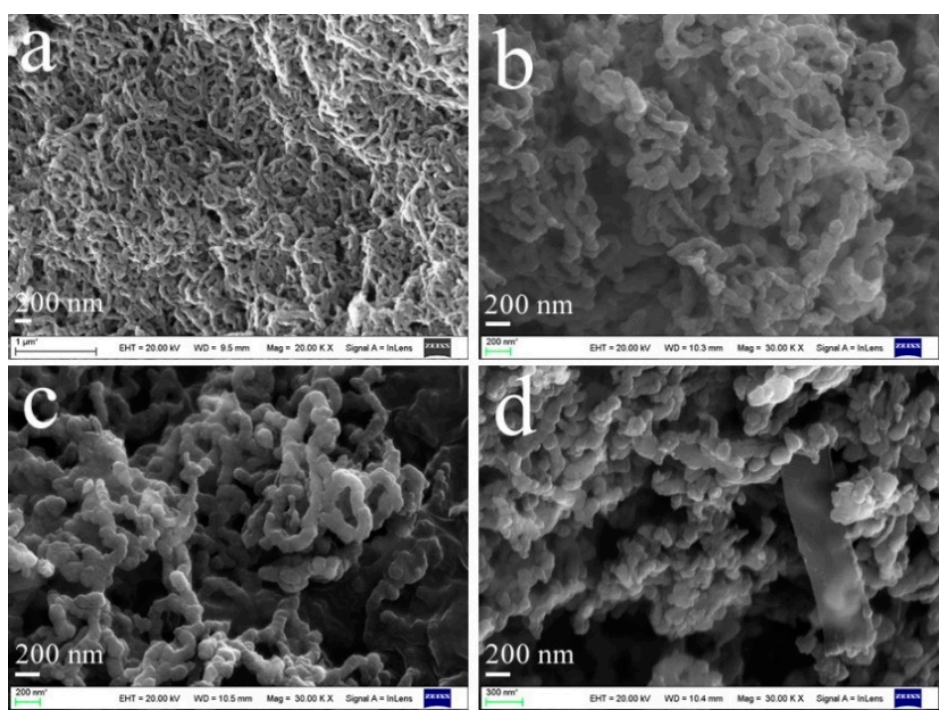

Figure 3. Scanning electron microscopy (SEM) images of the (a) PPyN, (b)PPyNG1, (c)PPyNG2, and (d) PPyNG3.

Figure 4 shows the evolution of open circuit potential (OCP) for coatings on mild steels in a $3.5 \%$ $\mathrm{NaCl}$ corrosive solution. The monitoring of OCP allowed for the assessment of the inclination of corrosion [39]. In the initial immersion, the OCP values exhibited a less negative potential for the Blank, EPPyN, and EPPyNG3 coatings, $(-0.3$ to $-0.45 \mathrm{~V})$, but the EPPyNG2 showed a more noble OCP value of around $-0.14 \mathrm{~V}$. This relative high potential demonstrated that EPPyNG2 provided excellent protective performance. The OCP value tended to decrease with the immersion time for all of the studied coatings. However, the lower rate of declination was observed in EPPyN, EPPyNG1, EPPyNG2, and EPPyNG3 when compared to the blank epoxy coating after immersion 20 days. It indicated that the oxidative PPy functional fillers passivated the steel, resulting in higher OCP [18]. The passivation layer effectively prevented the steel from corrosion. A few slight increases were observed for Blank and EPPyNG1 after immersion several days, probably due to the accumulation of corrosion products [23]. The potential of EPPyNG3 coating dropped sharply to $-0.70 \mathrm{~V}$ after immersion 20 days, revealing that excess graphene was detrimental to the anticorrosion property [40]. 


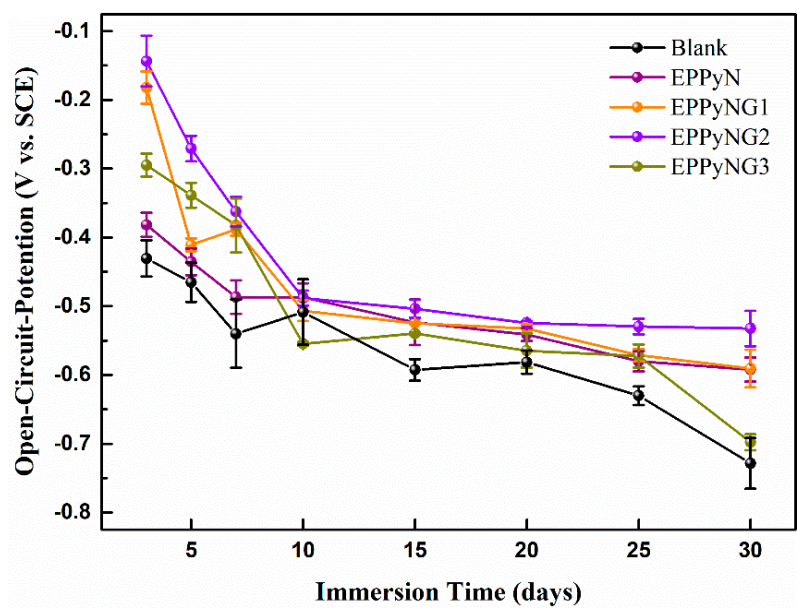

Figure 4. Evolution of open circuit potential (OCP) value for the samples with continuous immersion.

The potentiodynamic polarization tests were carried out to study the anticorrosion performance of EPPyNG composites coatings. Figure 5 shows the Tafel curves of the as prepared coatings immersion in corrosive solutions. Table 1 shows the electrochemical parameters that were obtained from Tafel curves. The corrosion current density $\left(I_{\text {corr }}\right)$, corrosion potential $\left(E_{\text {corr }}\right)$, anodic Tafel slope $\left(b_{\mathrm{a}}\right)$, and cathodic Tafel slope $\left(b_{c}\right)$ were estimated from the Tafel extrapolation of anodic and cathodic lines to the point of intersection. The more negative $E_{\text {corr }}$ and larger $I_{\text {corr }}$ suggested a faster corrosion rate, while the more positive $E_{\text {corr }}$ and the smaller $I_{\text {corr }}$ indicated a slower corrosion process [41]. The $E_{\text {corr }}$ of the neat epoxy resin coated mild steel was $-784 \mathrm{mV}$. A significantly positive shift $E_{\text {corr }}$ of $-565 \mathrm{mV}$ was obtained for the composites coating with PPyN, confirming that EPPyN engaged in redox reactions, resulting in the formation of metal oxide passive layer [20,42]. By addition of PPyNG, the $E_{\text {corr }}$ dramatically increased to $-537 \mathrm{mV}$ with $1 \mathrm{wt} \%$ graphene and $-482 \mathrm{mV}$ with $2 \mathrm{wt} \%$ graphene. Advanced corrosion protection effect of EPPyNG coating compared to EPPyN might arose from dispersing graphene nanosheets to increase the tortuosity of the diffusion pathway of $\mathrm{H}_{2} \mathrm{O}, \mathrm{O}_{2}$, and $\mathrm{Cl}^{-}$[43]. However, the coating with excess graphene (EPPyNG3) exhibited lower $E_{\text {corr }}$ than EPPyNG2, probably because larger fraction of graphene affected the growth of PPy nanowires and induced the defects in PPyNG3 composites [38], which was in agreement with the results of SEM. Furthermore, the higher $b_{\mathrm{a}} / b_{\mathrm{c}}$ ratio of EPPyNG2 was

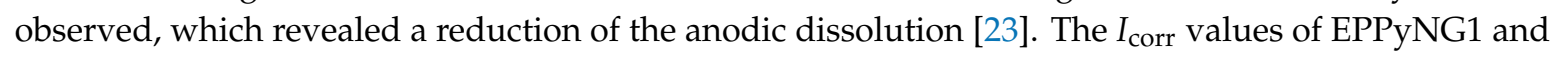
EPPyNG2 coated mild steel considerably decreased when compared with EPPyN. For the EPPyNG2 coatings, the $I_{\text {corr }}$ was lowest than other coatings, which indicated the best anticorrosion performance in all of the studied samples, which corresponded to results of OCP tests.

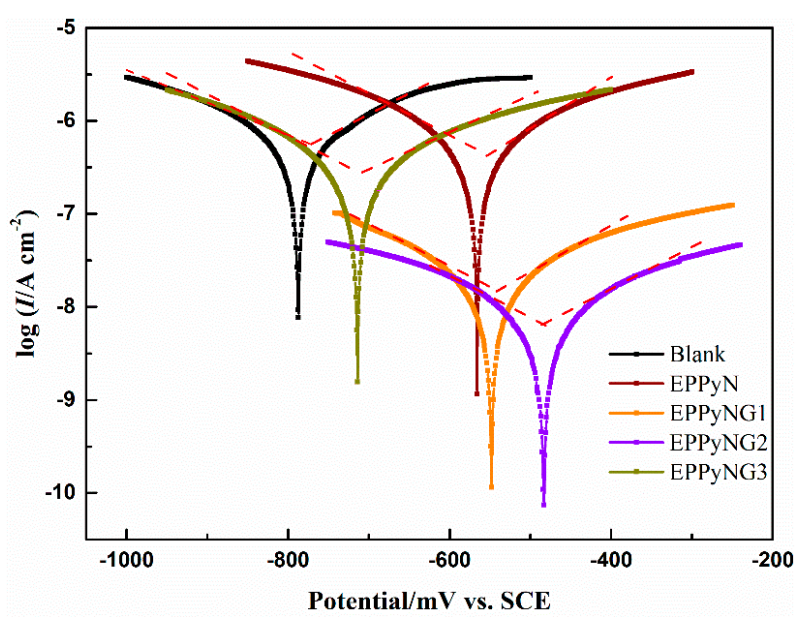

Figure 5. Tafel curves of coated mild steel. 
Table 1. Parameters of Tafel polarization curve for coated Q235 substrates.

\begin{tabular}{cccccccc}
\hline Sample & $\boldsymbol{E}_{\text {corr }}(\mathbf{m V})$ & $\begin{array}{c}\boldsymbol{I}_{\text {corr }} \\
\left(\mathbf{A} / \mathbf{c m}^{\mathbf{2}}\right)\end{array}$ & $\begin{array}{c}\boldsymbol{b}_{\mathbf{a}} \\
(\mathbf{m V} / \mathbf{d e c})\end{array}$ & $\begin{array}{c}\boldsymbol{b}_{\boldsymbol{c}} \\
(\mathbf{m V} / \mathbf{d e c})\end{array}$ & $\begin{array}{c}v_{\text {corr }} \\
(\mathbf{m m} / \mathbf{y e a r})\end{array}$ & $\begin{array}{c}\mathbf{R}_{\mathbf{p}}(\boldsymbol{\Omega} \\
\left.\mathbf{c m}^{\mathbf{2}}\right)\end{array}$ & $\mathbf{P E}(\mathbf{\%})$ \\
\hline Bare & -1019 & $1.1 \times 10^{-5}$ & 170.9 & -173.5 & 0.13 & $3.4 \times 10^{3}$ & - \\
Blank & -784 & $7.6 \times 10^{-7}$ & 193.8 & -221.8 & $8.8 \times 10^{-3}$ & $5.9 \times 10^{4}$ & 94.3 \\
EPPyN & -565 & $5.7 \times 10^{-7}$ & 201.4 & -195.3 & $6.6 \times 10^{-3}$ & $7.6 \times 10^{4}$ & 95.5 \\
EPPyNG1 & -537 & $1.9 \times 10^{-8}$ & 209.1 & -192.1 & $2.2 \times 10^{-4}$ & $2.3 \times 10^{6}$ & 99.8 \\
EPPyNG2 & -482 & $7.7 \times 10^{-9}$ & 203.9 & -193.9 & $8.9 \times 10^{-5}$ & $5.6 \times 10^{6}$ & 99.9 \\
EPPyNG3 & -713 & $3.0 \times 10^{-7}$ & 211.8 & -186.1 & $3.5 \times 10^{-3}$ & $1.4 \times 10^{5}$ & 97.6 \\
\hline
\end{tabular}

The quantitative analysis of Tafel curve was also investigated, and Table 1 summarizes the result. The corrosion rate, $v_{\text {corr }}(\mathrm{mm} /$ year) was obtained from Equation (1) [44]:

$$
v_{\text {corr }}=\frac{M I_{\text {corr }}}{n \rho} \times 3270
$$

where the molecular weight $(M)$ is $55.85 \mathrm{~g} / \mathrm{mol}$ for Q235, $I_{\text {corr }}$ is the corrosion current density $\left(\mathrm{A} / \mathrm{cm}^{2}\right)$, $n$ is 2 for the oxidation of steel, and the density $(\rho)$ is $7.85 \mathrm{~g} / \mathrm{cm}^{3}$ for Q235, 3270 is a constant. $R_{\mathrm{p}}$ is the polarization resistance calculated by the slope of the polarization curve at the $E_{\text {corr }}$ according to the Stern-Geary Equation (2) [45]:

$$
R_{\mathrm{p}}=\frac{b_{a} b_{c}}{2.303\left(b_{a}+b_{c}\right) I_{\text {corr }}}
$$

Here, $b_{\mathrm{a}}$ and $b_{\mathrm{c}}$ are the anodic and cathodic Tafel slopes, $I_{\text {corr }}$ is the corrosion current density. The protection efficiency (PE, \%) was calculated via Equation (3) [46]:

$$
\mathrm{PE}=\frac{R_{p}^{-1}(\text { bare })-R_{p}^{-1}(\text { coated })}{R_{p}^{-1}(\text { bare })} \times 100 \%
$$

where $R_{p}$ (bare) and $R_{p}$ (coated) denote the polarization resistance of bare and coated steel, respectively. Figure $\mathrm{S} 3$ shows the Tafel curve of bare steel.

The calculated $v_{\text {corr }}$ value of $8.9 \times 10^{-5} \mathrm{~mm} /$ year for EPPyNG2 was about 100 times lower than that for blank epoxy coating. The result of $v_{\text {corr }}$ demonstrated that the EPPyNG coatings displayed higher anticorrosion performance than epoxy coating with PPyN alone, and the best performance was achieved when the graphene-doped ratio was $2 \mathrm{wt} \%$. The mild steel that was coated with EPPyNG2 exhibited a $R_{\mathrm{p}}$ value of $5.6 \times 10^{6} \Omega \mathrm{cm}^{2}$, which was higher than that of bare mild steel, neat epoxy, EPPyN, EPPyNG1, and EPPyNG3 coated ones. In the case of protection efficiency, the highest PE value from EPPyNG2 (99.9\%) described that PPyNG2 loading in the epoxy coating can provide superior inhibition corrosion performance.

EIS is a powerful tool for investigating the corrosion protection of the coatings [47]. Figure 6 shows the Nyquist and Bode plots of the coated mild steels during different immersion days. For neat epoxy coating (Figure 6a), the Nyquist plots displayed two capacitive arcs after 15 days immersion, which indicated that the electrolyte was in contact with the metal surface. The first semicircle at high frequency region and the second part at middle-low frequency region were due to the impedance of coating and corrosion reactions, respectively [48]. The radius of capacitive impedance loop in high-frequency domain diminished during the immersion, which implied declined corrosion protective properties for mild steel. The EPPyN (Figure 6c), EPPyNG1 (Figure 6g), and EPPyNG3 (Figure 6i) showed the same trend. However, for the EPPyNG2 coating, the radius of capacitive impedance arc at low frequency region in the immersion seven days suddenly expanded beyond that of three days, which suggested that PPy might react to passivate the metal substrate [23]. The second semicircle was also observed after long time immersion for EPPyNG2, but its radius was significantly smaller than that of other coatings, which indicated less response from the pitting corrosion of the metal substrate [43]. 

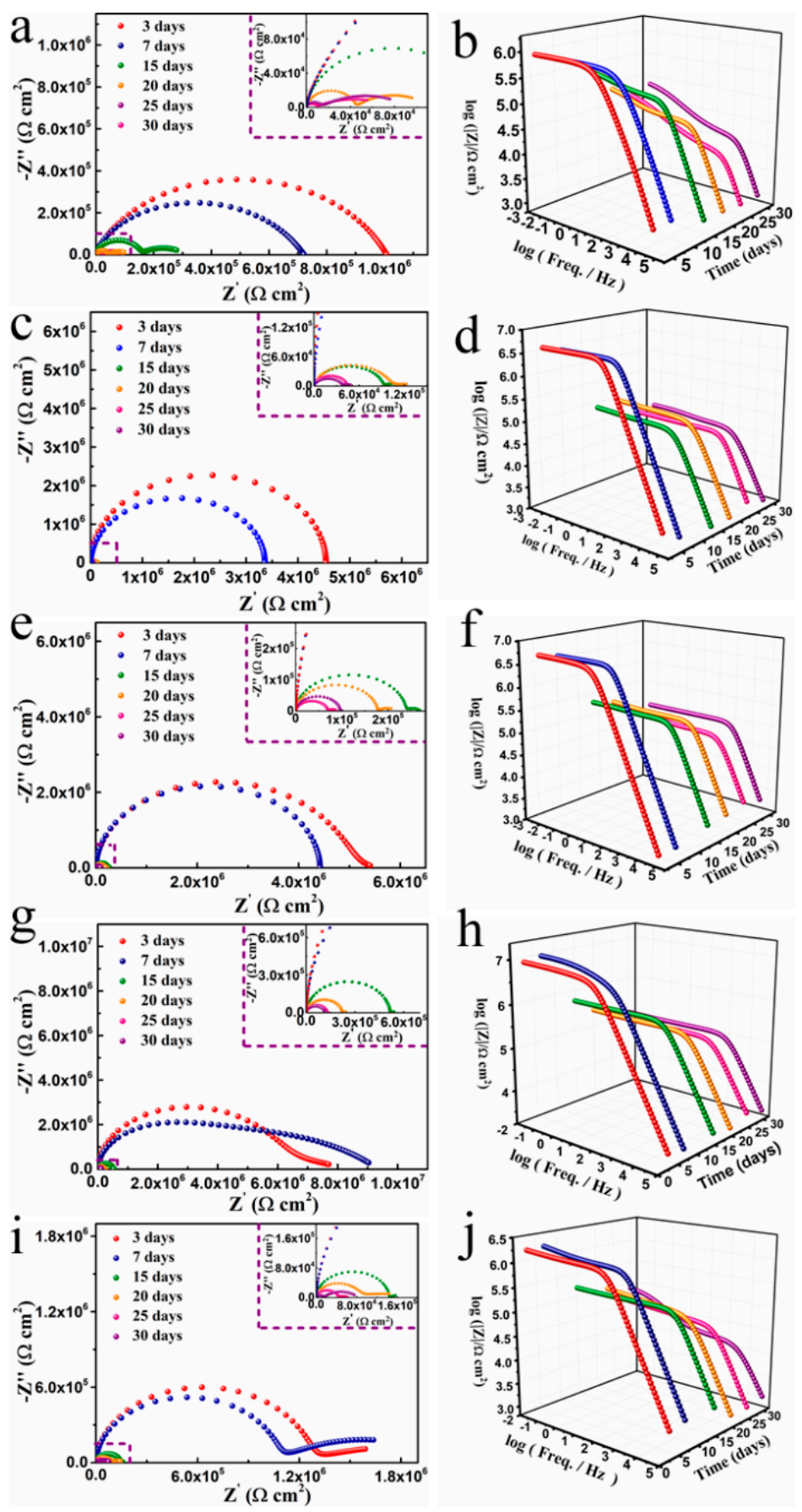

Figure 6. Nyquist and Bode plots of the coatings: (a,b) blank, (c,d) EPPyN, (e,f) EPPyNG1, (g,h) EPPyN2, and $(\mathbf{i}, \mathbf{j})$ EPPyNG3.

The impedance modulus at low frequency $\left(|\mathrm{Z}|_{0.01 \mathrm{~Hz}}\right)$ was used as a semi-quantitative standard of coating's protective performance for the Bode patterns [49], as summarized in Table 2. The impedance modulus dramatically decreased after 15 days and then progressively reduced with the increasing immersion time for all studied coatings, probably owing to the penetration of water and movement of ions through the coatings [50]. The $|\mathrm{Z}|_{0.01 \mathrm{~Hz}}$ of EPPyNG2 (Figure $6 \mathrm{~h}$ ), in the early immersion time, was up to $7.7 \times 10^{6} \Omega \mathrm{cm}^{2}$, higher than those of neat epoxy $\left(1.0 \times 10^{6} \Omega \mathrm{cm}^{2}\right)$. The EPPyNG2 coating had better barrier properties when compared to neat epoxy, because the well dispersed PPyNG could fill the structural and pinhole porosity of neat epoxy and then inhibited the water penetration. The conjugation length of EPPyNG2 was longer than those of EPPyN and EPPyNG1, which resulted in 
electrons easier delocalization and in favor of the formation of passivation layers [51,52]. Hence, the EPPyNG2 also exhibited better anticorrosion performance than those of EPPyN $\left(4.5 \times 10^{6} \Omega \mathrm{cm}^{2}\right)$ and EPPyNG1 $\left(5.4 \times 10^{6} \Omega \mathrm{cm}^{2}\right)$. Although EPPyNG3 possessed longer conjugation length, its excess graphene content might increase the defects due to influence of polypyrrole nanowires, and probably generated micro galvanic corrosion that showed the corrosion-promotion activity [53]. Therefore, the EPPyNG3 $\left(1.6 \times 10^{6} \Omega \mathrm{cm}^{2}\right)$ displayed worse anticorrosive property when compared with EPPyNG2. In addition, the impedance modulus of EPPyNG2 remained $1.2 \times 10^{5} \Omega \mathrm{cm}^{2}$ after 30 days, which was higher than other coatings.

Table 2. Results of electrochemical impedance spectroscopy (EIS) for coated Q235 substrates.

\begin{tabular}{ccccccc}
\hline \multirow{2}{*}{ Sample } & \multicolumn{5}{c}{$|\mathbf{Z}|_{\mathbf{0 . 0 1 H z}} \mathbf{( \Omega \mathbf { c m } ^ { \mathbf { 2 } } )}$} \\
\cline { 2 - 7 } & $\mathbf{3}$ days & $\mathbf{7}$ days & $\mathbf{1 5}$ days & $\mathbf{2 0}$ days & $\mathbf{2 5}$ days & $\mathbf{3 0}$ days \\
\hline Blank & $1.0 \times 10^{6}$ & $7.2 \times 10^{5}$ & $2.8 \times 10^{5}$ & $9.6 \times 10^{4}$ & $5.5 \times 10^{4}$ & $7.6 \times 10^{4}$ \\
EPPyN & $4.5 \times 10^{6}$ & $3.4 \times 10^{6}$ & $1.1 \times 10^{5}$ & $1.2 \times 10^{5}$ & $4.7 \times 10^{4}$ & $5.0 \times 10^{4}$ \\
EPPyNG1 & $5.4 \times 10^{6}$ & $4.4 \times 10^{6}$ & $2.7 \times 10^{5}$ & $2.1 \times 10^{5}$ & $8.9 \times 10^{4}$ & $1.0 \times 10^{5}$ \\
EPPyNG2 & $7.7 \times 10^{6}$ & $9.0 \times 10^{6}$ & $5.4 \times 10^{5}$ & $2.4 \times 10^{5}$ & $1.4 \times 10^{5}$ & $1.2 \times 10^{5}$ \\
EPPyNG3 & $1.6 \times 10^{6}$ & $1.6 \times 10^{6}$ & $1.6 \times 10^{5}$ & $1.4 \times 10^{5}$ & $6.2 \times 10^{4}$ & $7.6 \times 10^{4}$ \\
\hline
\end{tabular}

Moreover, ZSimpWin software further fitted the EIS measurements while using the equivalent electric circuits, as shown in Figure 7. The electrical equivalent circuits were composed of $R_{\mathrm{s}}, R_{\text {pore }}, R_{\mathrm{ct}}$, $Z_{\mathrm{w}}, Q_{\mathrm{c}}$, and $Q_{\mathrm{dl}}$, which represented the solution resistance, pore resistance, charge-transfer resistance, Warburg impedance, and the constant phase elements substituted for the coating capacitance $\left(C_{c}\right)$ and double-layer (steel/solution) capacitance $\left(C_{\mathrm{dl}}\right)$, respectively. $R_{\text {pore }}$ modeled ionically conducting paths across the coating, which could be used to evaluate the barrier performance of the coatings [54]. Models (a) and (b) were fitted with the EIS data of pure epoxy coating and composites coatings, respectively.
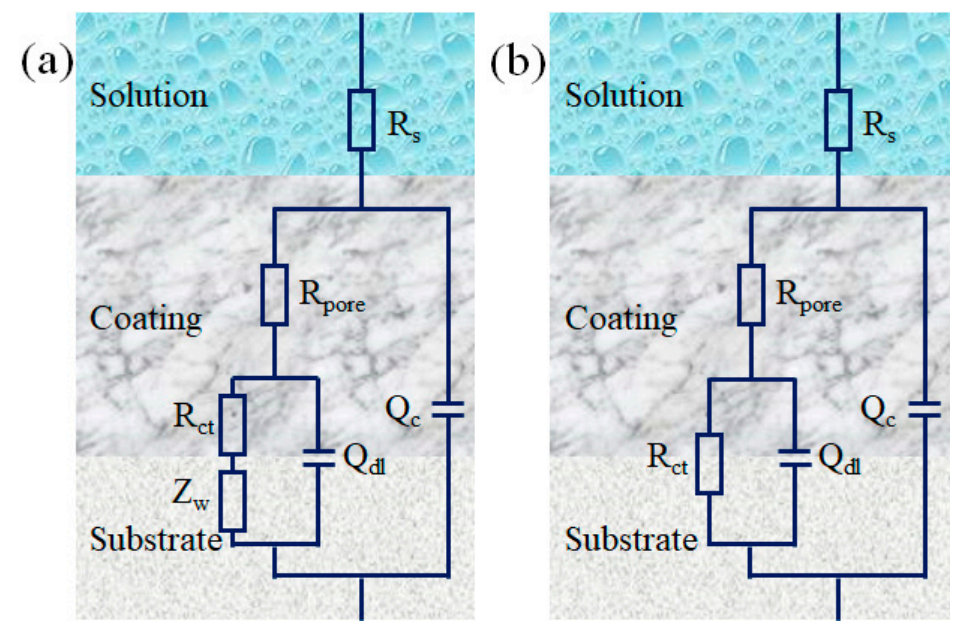

Figure 7. (a,b) Equivalent electrical circuits of the coatings.

Figure 8 shows the time-dependent behavior of $R_{\text {pore }}$ and $C_{\mathrm{c}}$ on the basis of the above fitting models. Generally, a higher $R_{\text {pore }}$ and lower $C_{\mathrm{c}}$ suggested that a small amount of corrosive media penetrated into the coatings [55]. It could be observed that the $R_{\text {pore }}$ of neat epoxy coating gradually decreased from $7.3 \times 10^{5} \Omega \mathrm{cm}^{2}$ to a much lower value $\left(1.3 \times 10^{4} \Omega \mathrm{cm}^{2}\right)$. The $R_{\text {pore }}$ of coatings with EPPyN, EPPyNG1, and EPPyNG3 decreased to some extent, while the EPPyNG2 coating always maintained much higher values. The $C_{\mathrm{c}}$ of pure epoxy coating continuously increased from $3.1 \times 10^{-9} \mathrm{~F} / \mathrm{cm}^{2}$ to $1.1 \times 10^{-8} \mathrm{~F} / \mathrm{cm}^{2}$. In contrast, the EPPyNG2 displayed a much lower $C_{\mathrm{c}}$ value when compared to those of neat epoxy and EPPyN coating. The EPPyNG3 coating also exhibited lower $R_{\text {pore }}$ and higher $C_{c}$ than EPPyNG2, which confirmed that excess graphene induced the defect coating and reduced 
corrosion protection. Consequently, it could be concluded that the EPPyNG2 composite coating showed the outstanding corrosion resistance, which was in agreement with the potentiodynamic polarization results.
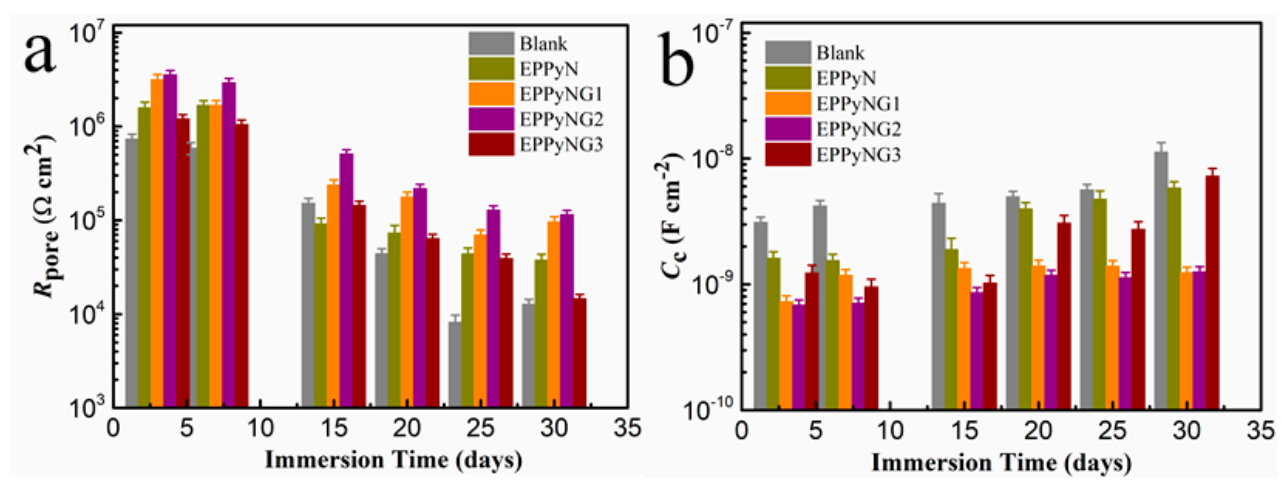

Figure 8. (a) $R_{\text {pore }}$ and (b) $C_{\mathrm{c}}$ values with immersion in $3.5 \mathrm{wt} \% \mathrm{NaCl}$ solution.

According to the above results, Figure 9 demonstrates the mechanism of corrosion protection for the mild steel substrate with neat epoxy coating and PPyNG nanocomposite coatings. For pure epoxy coating, corrosive mediums $\left(\mathrm{H}_{2} \mathrm{O}, \mathrm{O}_{2}\right.$, and $\mathrm{Cl}^{-}$, etc.) could penetrate the coating easily due to the minute crevices of the surface. However, the well-dispersed PPyNG composite, as an anti-corrosion barrier, repaired the cracks of epoxy coating, and enhanced the tortuosity of the diffusion pathway at a great extent. Furthermore, PPyN reacted with steel to form a dense layer of passive oxide film, which resulted in substantially reduced penetration of corrosive medias. Hence, the anti-corrosion performance of the EPPyNG nanocomposite coatings was significantly improved.
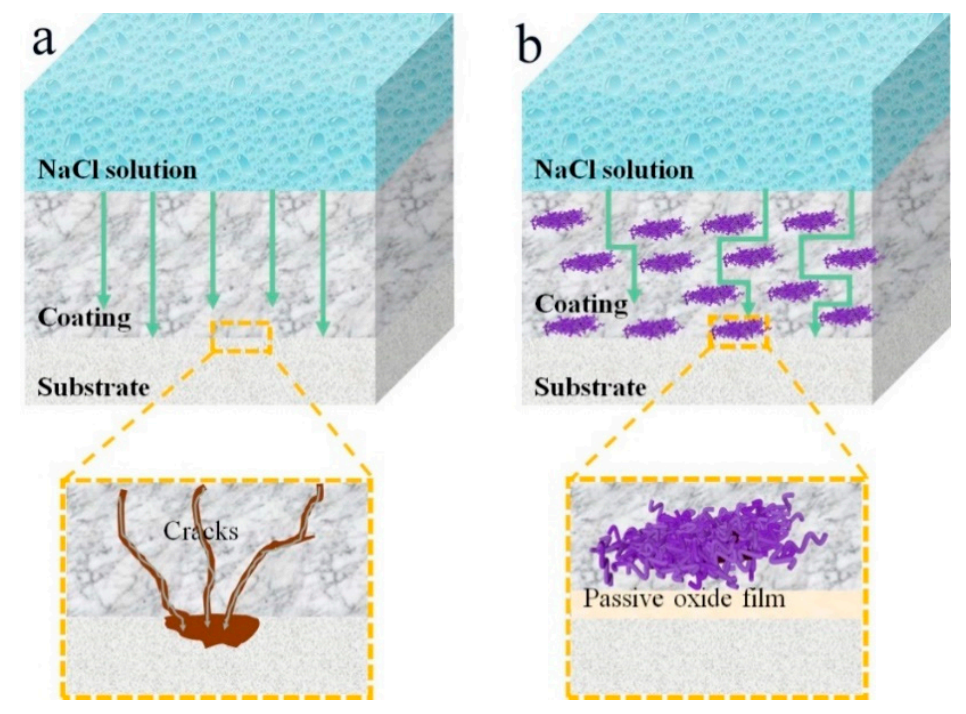

Figure 9. Schematic illustration of corrosion protection of the mild steel with (a) neat epoxy coating and (b) EPPyNG composite coating.

\section{Conclusions}

In this study, the PPy nanowires were synthesized while using CTAB as soft template, and combined with graphene nanosheets by in situ oxidation polymerization. The incorporation of PPy nanowires/graphene into waterborne epoxy on mild steel substrate was performed. Potentiodynamic polarization plots, impedance measurements, and fitted $R_{\text {pore }}$ and $C_{\mathrm{c}}$ were used to study the anticorrosion performance of the coatings. The PPy nanowires/graphene nanocomposite coating exhibited improved anticorrosion performance in comparison with pure epoxy and epoxy/PPy 
nanowires samples. The passivation effect of the PPy nanowires contributed to the effective inhibiting corrosive effect. Meanwhile, the well-dispersed PPyNG could block the coating pores and decrease the corrosive medias diffusion toward the substrate. Therefore, PPy nanowires/graphene nanocomposite would be used as a promising anticorrosion pigment.

Supplementary Materials: The following are available online at http://www.mdpi.com/2073-4360/11/12/1998/s1, Figure S1: t Water absorption of epoxy/polypyrrole nanowires coatings filled with $0 \%, 0.3 \%, 0.5 \%$ and $0.7 \%$ polypyrrole nanowires., Figure S2: Tafel curves of mild steel with coatings of epoxy/polypyrrole nanowires coatings filled with $0 \%, 0.3 \%, 0.5 \%$ and $0.7 \%$ polypyrrole nanowires in $3.5 \%$ sodium chloride solution after 20 days. Figure S3: Tafel curve of the bare mild steel electrode. Figure S4. Optical microscopic images of epoxy/polypyrrole nanowires coatings filled with $0 \%, 0.3 \%, 0.5 \%$ and $0.7 \%$ polypyrrole nanowires.

Author Contributions: Investigation, Y.D. and J.Z.; methodology, P.X.; validation, J.R.; formal analysis, H.Z.; resources, W.Z. and J.W.; data curation, Y.D.; writing—original draft preparation, J.Z.; writing-review and editing, J.Z. and Y.D.; supervision, Z.C.; project administration, J.Z. and H.H.; funding acquisition, J.Z., F.G. and L.S.

Funding: This research was funded by Natural Science Foundation of Jiangxi Education Department (Contract No. GJJ170680), National Natural Science Foundation of China (Contract No. 51563011 and 2170436).

Acknowledgments: We thank Jiangxi Key Laboratory of Surface Engineering for SEM characterization.

Conflicts of Interest: The authors declare no conflict of interest.

\section{References}

1. Williams, G.; Geary, S.; McMurray, H.N. Smart release corrosion inhibitor pigments based on organic ion-exchange resins. Corros. Sci. 2012, 57, 139-147. [CrossRef]

2. Grundmeier, G.; Schmidt, W.; Stratmann, M. Corrosion protection by organic coatings: Electrochemical mechanism and novel methods of investigation. Electrochim. Acta 2000, 45, 2515-2533. [CrossRef]

3. Shchukin, D.G.; Zheludkevich, M.; Yasakau, K.; Lamaka, S.; Ferreira, M.G.S.; Möhwald, H. Layer-by-Layer Assembled Nanocontainers for Self-Healing Corrosion Protection. Adv. Mater. 2006, 18, 1672-1678. [CrossRef]

4. Navarchian, A.H.; Joulazadeh, M.; Karimi, F. Investigation of corrosion protection performance of epoxy coatings modified by polyaniline/clay nanocomposites on steel surfaces. Prog. Org. Coat. 2014, 77, 347-353. [CrossRef]

5. Gu, H.; Ma, C.; Gu, J.; Guo, J.; Yan, X.; Huang, J.; Zhang, Q.; Guo, Z. An overview of multifunctional epoxy nanocomposites. J. Mater. Chem. C 2016, 4, 5890-5906. [CrossRef]

6. Contri, G.; Barra, G.M.O.; Ramoa, S.D.A.S.; Merlini, C.; Ecco, L.G.; Souza, F.S.; Spinelli, A. Epoxy coating based on montmorillonite-polypyrrole: Electrical properties and prospective application on corrosion protection of steel. Prog. Org. Coat. 2018, 114, 201-207. [CrossRef]

7. Kumar, A.; Ghosh, P.K.; Yadav, K.L.; Kumar, K. Thermo-mechanical and anti-corrosive properties of MWCNT/epoxy nanocomposite fabricated by innovative dispersion technique. Compos. Part. B Eng. 2017, 113, 291-299. [CrossRef]

8. Chen, C.; Qiu, S.; Cui, M.; Qin, S.; Yan, G.; Zhao, H.; Wang, L.; Xue, Q. Achieving high performance corrosion and wear resistant epoxy coatings via incorporation of noncovalent functionalized graphene. Carbon 2017, 114, 356-366. [CrossRef]

9. Hao, Y.; Sani, L.A.; Ge, T.; Fang, Q. Phytic acid doped polyaniline containing epoxy coatings for corrosion protection of Q235 carbon steel. Appl. Surf. Sci. 2017, 419, 826-837. [CrossRef]

10. Naveen, M.H.; Gurudatt, N.G.; Shim, Y.-B. Applications of conducting polymer composites to electrochemical sensors: A review. Appl. Mater. Today 2017, 9, 419-433. [CrossRef]

11. Lei, Y.; Qiu, Z.; Liu, J.; Li, D.; Tan, N.; Liu, T.; Zhang, Y.; Chang, X.; Gu, Y.; Yin, Y. Effect of Conducting Polyaniline/Graphene Nanosheet Content on the Corrosion Behavior of Zinc-Rich Epoxy Primers in 3.5\% NaCl Solution. Polymers 2019, 11, 850. [CrossRef] [PubMed]

12. Nguyen Thi, T.; Dinh Thi Mai, T.; Pham Thi, N.; Nguyen Thu, P.; Vu Thi Hai, V.; Ngo Quang, M. Enhanced Anti-Corrosion Protection of Carbon Steel with Silica-Polypyrrole-Dodecyl Sulfate Incorporated into Epoxy Coating. J. Electron. Mater. 2019, 48, 3931-3938. [CrossRef]

13. Huang, Y.; Li, H.; Wang, Z.; Zhu, M.; Pei, Z.; Xue, Q.; Huang, Y.; Zhi, C. Nanostructured Polypyrrole as a flexible electrode material of supercapacitor. Nano Energy 2016, 22, 422-438. [CrossRef] 
14. Jadhav, N.; Vetter, C.A.; Gelling, V.J. The effect of polymer morphology on the performance of a corrosion inhibiting polypyrrole/aluminum flake composite pigment. Electrochim. Acta 2013, 102, 28-43. [CrossRef]

15. Armelin, E.; Pla, R.; Liesa, F.; Ramis, X.; Iribarren, J.I.; Alemán, C. Corrosion protection with polyaniline and polypyrrole as anticorrosive additives for epoxy paint. Corros. Sci. 2008, 50, 721-728. [CrossRef]

16. Kalendová, A.; Veselý, D.; Kohl, M.; Stejskal, J. Anticorrosion efficiency of zinc-filled epoxy coatings containing conducting polymers and pigments. Prog. Org. Coat. 2015, 78, 1-20. [CrossRef]

17. Gergely, A.; Pfeifer, É.; Bertóti, I.; Török, T.; Kálmán, E. Corrosion protection of cold-rolled steel by zinc-rich epoxy paint coatings loaded with nano-size alumina supported polypyrrole. Corros. Sci. 2011, 53, 3486-3499. [CrossRef]

18. Kalendová, A.; Veselý, D.; Kohl, M.; Stejskal, J. Effect of surface treatment of pigment particles with polypyrrole and polyaniline phosphate on their corrosion inhibiting properties in organic coatings. Prog. Org. Coat. 2014, 77, 1465-1483. [CrossRef]

19. Jiang, S.; Liu, Z.; Jiang, D.; Cheng, H.; Han, J.; Han, S. Graphene as a nanotemplating auxiliary on the polypyrrole pigment for anticorrosion coatings. High Perform. Polym. 2016, 28, 747-757. [CrossRef]

20. Yeh, J.-M.; Chin, C.-P.; Chang, S. Enhanced corrosion protection coatings prepared from soluble electronically conductive polypyrrole-clay nanocomposite materials. J. Appl. Polym. Sci. 2003, 88, 3264-3272. [CrossRef]

21. Martin-Gallego, M.; Verdejo, R.; Lopez-Manchado, M.A.; Sangermano, M. Epoxy-Graphene UV-cured nanocomposites. Polymer 2011, 52, 4664-4669. [CrossRef]

22. Kugler, S.; Kowalczyk, K.; Spychaj, T. Influence of synthetic and bio-based amine curing agents on properties of solventless epoxy varnishes and coatings with carbon nanofillers. Prog. Org. Coat. 2017, 109, 83-91. [CrossRef]

23. Qiu, S.; Li, W.; Zheng, W.; Zhao, H.; Wang, L. Synergistic Effect of Polypyrrole-Intercalated Graphene for Enhanced Corrosion Protection of Aqueous Coating in 3.5\% NaCl Solution. ACS Appl. Mater. Interfaces 2017, 9, 34294-34304. [CrossRef]

24. Ma, G.; Wen, Z.; Wang, Q.; Shen, C.; Peng, P.; Jin, J.; Wu, X. Enhanced performance of lithium sulfur battery with self-assembly polypyrrole nanotube film as the functional interlayer. J. Power Sources 2015, 273, 511-516. [CrossRef]

25. Lee, J.I.; Cho, S.H.; Park, S.-M.; Kim, J.K.; Kim, J.K.; Yu, J.-W.; Kim, Y.C.; Russell, T.P. Highly Aligned Ultrahigh Density Arrays of Conducting Polymer Nanorods using Block Copolymer Templates. Nano Lett. 2008, 8, 2315-2320. [CrossRef]

26. Berdichevsky, Y.; Lo, Y.H. Polypyrrole Nanowire Actuators. Adv. Mater. 2006, 18, 122-125. [CrossRef]

27. Dubal, D.P.; Caban-Huertas, Z.; Holze, R.; Gomez-Romero, P. Growth of polypyrrole nanostructures through reactive templates for energy storage applications. Electrochim. Acta 2016, 191, 346-354. [CrossRef]

28. Ma, Z.; Chen, P.; Cheng, W.; Yan, K.; Pan, L.; Shi, Y.; Yu, G. Highly Sensitive, Printable Nanostructured Conductive Polymer Wireless Sensor for Food Spoilage Detection. Nano Lett. 2018, 18, 4570-4575. [CrossRef]

29. Dong, L.; Chen, Z.; Zhao, X.; Ma, J.; Lin, S.; Li, M.; Bao, Y.; Chu, L.; Leng, K.; Lu, H.; et al. A non-dispersion strategy for large-scale production of ultra-high concentration graphene slurries in water. Nat. Commun. 2018, 9, 76. [CrossRef]

30. Liu, L.; Zhao, C.; Zhao, Y.; Jia, N.; Zhou, Q.; Yan, M.; Jiang, Z. Characteristics of polypyrrole (PPy) nano-tubules made by templated ac electropolymerization. Eur. Polym. J. 2005, 41, 2117-2121. [CrossRef]

31. Lei, W.; He, P.; Wang, Y.; Zhang, S.; Dong, F.; Liu, H. Soft template interfacial growth of novel ultralong polypyrrole nanowires for electrochemical energy storage. Electrochim. Acta 2014, 132, 112-117. [CrossRef]

32. Zhang, L.L.; Zhao, S.; Tian, X.N.; Zhao, X.S. Layered Graphene Oxide Nanostructures with Sandwiched Conducting Polymers as Supercapacitor Electrodes. Langmuir 2010, 26, 17624-17628. [CrossRef]

33. Zhong, W.; Liu, S.; Chen, X.; Wang, Y.; Yang, W. High-Yield Synthesis of Superhydrophilic Polypyrrole Nanowire Networks. Macromolecules 2006, 39, 3224-3230. [CrossRef]

34. Gnana kumar, G.; Kirubaharan, C.J.; Udhayakumar, S.; Ramachandran, K.; Karthikeyan, C.; Renganathan, R.; Nahm, K.S. Synthesis, Structural, and Morphological Characterizations of Reduced Graphene Oxide-Supported Polypyrrole Anode Catalysts for Improved Microbial Fuel Cell Performances. ACS Sustain. Chem. Eng. 2014, 2, 2283-2290. [CrossRef]

35. Zhong, J.; Gao, S.; Xue, G.; Wang, B. Study on Enhancement Mechanism of Conductivity Induced by Graphene Oxide for Polypyrrole Nanocomposites. Macromolecules 2015, 48, 1592-1597. [CrossRef] 
36. Pasquier, A.D.; Orsini, F.; Gozdz, A.S.; Tarascon, J.M. Electrochemical behaviour of LiMn2O4-PPy composite cathodes in the 4-V region. J. Power Sources 1999, 81-82, 607-611. [CrossRef]

37. Singu, B.S.; Yoon, K.R. Highly exfoliated GO-PPy-Ag ternary nanocomposite for electrochemical supercapacitor. Electrochim. Acta 2018, 268, 304-315. [CrossRef]

38. Li, J.; Xie, H.; Li, Y. Fabrication of graphene oxide/polypyrrole nanowire composite for high performance supercapacitor electrodes. J. Power Sources 2013, 241, 388-395. [CrossRef]

39. Hosseini, M.G.; Sabouri, M.; Shahrabi, T. Comparison of the corrosion protection of mild steel by polypyrrole-phosphate and polypyrrole-tungstenate coatings. J. Appl. Polym. Sci. 2008, 110, 2733-2741. [CrossRef]

40. Dutta, D.; Ganda, A.N.F.; Chih, J.-K.; Huang, C.-C.; Tseng, C.-J.; Su, C.-Y. Revisiting graphene-polymer nanocomposite for enhancing anticorrosion performance: A new insight into interface chemistry and diffusion model. Nanoscale 2018, 10, 12612-12624. [CrossRef]

41. Wei, H.; Ding, D.; Wei, S.; Guo, Z. Anticorrosive conductive polyurethane multiwalled carbon nanotube nanocomposites. J. Mater. Chem. A 2013, 1, 10805-10813. [CrossRef]

42. Gharibi, R.; Yousefi, M.; Yeganeh, H. Synthesis, characterization and assessment of poly(urethane-co-pyrrole)s derived from castor oil as anticorrosion coatings for stainless steel. Prog. Org. Coat. 2013, 76, 1454-1464. [CrossRef]

43. Liu, S.; Gu, L.; Zhao, H.; Chen, J.; Yu, H. Corrosion Resistance of Graphene-Reinforced Waterborne Epoxy Coatings. J. Mater. Sci. Technol. 2016, 32, 425-431. [CrossRef]

44. Yeh, T.-C.; Huang, T.-C.; Huang, H.-Y.; Huang, Y.-P.; Cai, Y.-T.; Lin, S.-T.; Wei, Y.; Yeh, J.-M. Electrochemical investigations on anticorrosive and electrochromic properties of electroactive polyurea. Polym. Chem. 2012, 3, 2209-2216. [CrossRef]

45. Huang, T.-C.; Yeh, T.-C.; Huang, H.-Y.; Ji, W.-F.; Lin, T.-C.; Chen, C.-A.; Yang, T.-I.; Yeh, J.-M. Electrochemical investigations of the anticorrosive and electrochromic properties of electroactive polyamide. Electrochim. Acta 2012, 63, 185-191. [CrossRef]

46. Tüken, T.; Arslan, G.; Yazıc1, B.; Erbil, M. The corrosion protection of mild steel by polypyrrole/polyphenol multilayer coating. Corros. Sci. 2004, 46, 2743-2754. [CrossRef]

47. Liu, C.; Bi, Q.; Matthews, A. EIS comparison on corrosion performance of PVD TiN and CrN coated mild steel in $0.5 \mathrm{~N} \mathrm{NaCl}$ aqueous solution. Corros. Sci. 2001, 43, 1953-1961. [CrossRef]

48. Arefinia, R.; Shojaei, A.; Shariatpanahi, H.; Neshati, J. Anticorrosion properties of smart coating based on polyaniline nanoparticles/epoxy-ester system. Prog. Org. Coat. 2012, 75, 502-508. [CrossRef]

49. Liu, T.; Li, J.; Li, X.; Qiu, S.; Ye, Y.; Yang, F.; Zhao, H. Effect of self-assembled tetraaniline nanofiber on the anticorrosion performance of waterborne epoxy coating. Prog. Org. Coat. 2019, 128, 137-147. [CrossRef]

50. Ghanbari, A.; Attar, M.M. A study on the anticorrosion performance of epoxy nanocomposite coatings containing epoxy-silane treated nano-silica on mild steel substrate. J. Ind. Eng. Chem. 2015, 23, 145-153. [CrossRef]

51. Montoya, P.; Jaramillo, F.; Calderón, J.; Córdoba de Torresi, S.I.; Torresi, R.M. Evidence of redox interactions between polypyrrole and $\mathrm{Fe} 3 \mathrm{O} 4$ in polypyrrole-Fe3O4 composite films. Electrochim. Acta 2010, 55, 6116-6122. [CrossRef]

52. Mohammadkhani, R.; Ramezanzadeh, M.; Saadatmandi, S.; Ramezanzadeh, B. Designing a dual-functional epoxy composite system with self-healing/barrier anti-corrosion performance using graphene oxide nano-scale platforms decorated with zinc doped-conductive polypyrrole nanoparticles with great environmental stability and non-toxicity. Chem. Eng. J. 2020, 382, 122819.

53. Ding, J.; Zhao, H.; Xu, B.; Zhao, X.; Su, S.; Yu, H. Superanticorrosive Graphene Nanosheets through $\pi$ Deposition of Boron Nitride Nanodots. ACS Sustain. Chem. Eng. 2019, 7, 10900-10911. [CrossRef]

54. Qiu, S.; Chen, C.; Cui, M.; Li, W.; Zhao, H.; Wang, L. Corrosion protection performance of waterborne epoxy coatings containing self-doped polyaniline nanofiber. Appl. Surf. Sci. 2017, 407, 213-222. [CrossRef]

55. Zhang, Y.; Shao, Y.; Zhang, T.; Meng, G.; Wang, F. High corrosion protection of a polyaniline/organophilic montmorillonite coating for magnesium alloys. Prog. Org. Coat. 2013, 76, 804-811. [CrossRef]

(C) 2019 by the authors. Licensee MDPI, Basel, Switzerland. This article is an open access article distributed under the terms and conditions of the Creative Commons Attribution (CC BY) license (http://creativecommons.org/licenses/by/4.0/). 